\title{
The Cross-Culture Management of Chinese Enterprises in Poland Under the Belt and Road Initiative-Based on PEST Model
}

\author{
Guiyu Dai ${ }^{1}, \mathrm{Yi} \mathrm{Cai}^{2}$ \\ ${ }^{1}$ Center for Foreign Literature and Culture, School of English for International Business at Guangdong \\ University of Foreign Studies, Guangzhou, China \\ ${ }^{2}$ School of English for International Business at Guangdong University of Foreign Studies, Guangzhou, China \\ Correspondence: Yi Cai, School of English for International Business at Guangdong University of Foreign \\ Studies, Guangzhou, China.
}

Received: July 10, 2017

Accepted: August 2, 2017

Online Published: August 14, 2017

doi:10.5539/ibr.v10n9p96

URL: https://doi.org/10.5539/ibr.v10n9p96

\begin{abstract}
"The Belt and Road Initiative" not only provides great opportunities but also poses enormous challenges to Chinese enterprises for further development. Along the Belt and the Road, there are different countries with unique culture characteristics, which will be the difficult challenges Chinese enterprises have to face in the overseas investment. The present study will combine PEST (Political, Economic, Social and Technological) model with Hofstede's culture dimensions as the theoretical basis for analyzing the potential opportunities and challenges Chinese enterprises tend to confront in Poland. Based on a detailed analysis of the opportunities and challenges, this writing proposes three tentative cross-culture management strategies: (1) Investigating the local markets and identifying the culture differences; (2) Cultivating intercultural communication competence of the cross-culture employees; (3) Acculturating to the local society and making innovation based on culture fusion, which would be referential for Chinese enterprises to seek investment opportunities in the countries along the Belt and the Road.
\end{abstract}

Keywords: the belt and road initiative, cross-culture management, PEST analysis, Poland

\section{Introduction}

The Belt and Road, which refers to the Silk Road Economic Belt (SREB) and the $21^{\text {st }}$ century Maritime Silk Road (MSR), was proposed by President Xi in September 2013, concentrating on connectivity and cooperation among countries primarily in Eurasia. The Silk Road Economic Belt (SREB) includes three international corridors: the first one starts from China and bounds for Europe via Central Asia and Russia; the second one passes through Central Asia and West Asia arriving at the Persian Gulf and Mediterranean; the third one is from China to Southeast Asia, South Asia and the Indian Ocean. Meanwhile, the 21st century Maritime Silk Road (MSR) comprises two routes. The one traverses from the South China Sea and Indian Ocean and extends to Europe and the other reaches South Pacific via Indian Ocean. Countries along the Belt and the Road are mostly developing countries and emerging economies which are in the period of social economic transition, such as Thailand, India, Bangladesh, Poland, Czech Republic, Romania, etc. (Sun \& Liu, 2017).

In 2014, the Silk Road Fund as well as the Asia Infrastructure Investment Bank was established to provide necessary support for the infrastructure construction for relevant countries. A series of steps taken by the Chinese government are sure to bring golden opportunities to the local enterprises to edge into the international world and strive for greater development. Besides, in order to response to Chinese policies, the governments from other countries have also brought out relevant policies to support the investment.

Poland is referred to as the "gateway" of Europe. Being the converging point of East Europe and West Europe, Poland plays a significant role in actively establishing cooperative relationship among countries along the route (Wei, 2015). It is the only country in Europe whose economy keeps developing during the last 20 years with a high growth rate of annual GDP, which has laid a solid foundation for the cooperation between two countries. In 2011, Poland and China has established Strategic Partnership and now it becomes the biggest trade partner of China in Central and Eastern Europe (Du \& Huang, 2015); China, at the same time, is Poland's biggest trade partner in Asia, all of which has demonstrated the sound development momentum between two countries. 
In the process of investment in Poland, Chinese enterprises will witness great opportunities, but at the time, will face a lot of cultural challenges (social factors) for Polish people have their own way of doing business and their own cultural conventions. Those are the reasons why Poland is chosen as the target country of case analysis in this paper. Through the case analysis, the current research will try to propose some feasible cross-culture management strategies in the overseas investment, especially in the investment of Poland.

\section{Literature Review}

\subsection{Previous Study on the Cross-Culture Management}

Cross-Culture Management is a newly-emerged interdisciplinary subject gradually developed in America in the late 1970's. With the deepening of globalization, more and more enterprises are seeking investment in the international world and are attaching even greater importance to the cross-culture management so as to make profits through handling cultural discrepancies and formulating appropriate acculturation strategies. According to the American scholar David A. Ricks, "Most of the failure of the multinational corporations is caused by neglecting the basic and subtle understanding of culture differences (Guan, 2012)." Many scholars have proposed their own strategies of cross-culture management in a general sense. Tang (2005) has summed up some feasible strategies for the reference of Chinese enterprises after analyzing the cross cultural management in foreign countries. Those strategies are as follows: making cross-culture management strategy; identifying the cultural differences by analyzing from different culture dimensions; conducting cross-culture management training; establishing communication mechanism; innovating based on culture integration. In the article Intercultural Shock and Inter-Cultural Management, Li (2006) has expounded the de velopment of intercultural enterprise management, pointing out that the core of which is intercultural shock management. He has further analyzed that the culture shock mainly resulted from the following three reasons: (1) different values; (2) intercultural communication barriers (stereotype, ethnocentrism, etc.); (3) different ways of thinking and working, etc. He has also provided some feasible intercultural management strategies, such as arousing people's awareness of cross-culture management, unifying the values within the enterprise, adopting the localization management strategy, and learning the foreign culture, in which he accentuated the importance of cross cultural training.

Some other scholars have taken a country or an enterprise as an example to analyze the specific cultural differences and strategies, which has narrowed down the scope and makes the study more concrete. For example, by combining qualitative research method and quantitative research method in his article Cross-Cultural Management Research of Thai Enterprise to Enter the Chinese Market, Zhao (2014) compares the culture differences between China and Thailand, and comes to the conclusions that: (1) The enterprise should first identify the different management styles and cultivate the cross-cultural management awareness; (2) Emphasis should be given to the acculturation and localization; (3) Cross-cultural training should be conducted to cultivate employees' intercultural communicative competence so that culture conflicts will be alleviated; (4) Cultural fusion is the core of cross cultural management, and is the most effective way to address culture conflicts. Gu (2011) has taken the successful cross-culture management of the Coca Cola Company of China as an example, illustrating how to manage the multinational corporation internationally and cross-culturally.

\subsection{Previous Study on the Cross-Culture Management under the Belt and Road Initiative}

As the Belt and Road Initiative is a newly proposed policy late in 2013, few researches have been done from the perspective of cross-culture management. According to our knowledge, up to now, there are mainly two scholars who have attempted to make research from this aspect.

Taking Hofestede's culture dimensions as his theoretical basis and combining with the national geographic distribution, Gao (2015) analyzed the culture difference among different countries along the Belt and the Road and proposed cross-culture management strategy for Chinese enterprises to go out. Yang, Chen, Lin and Song (2016) believed that culture conflicts in cross-culture management mainly result from ethnocentrism, differences of customs and religions, value divergence, and communication barriers, and the effective ways of alleviating culture conflicts are identifying culture differences, conducting intercultural training and encouraging talent localization.

The above two scholars have explored cross-culture management strategies based on the analysis of the countries along the Belt and the Road as well as their cultural differences; however, the countries involved are extensive and their analyses of culture differences are rather general and their strategies are less concrete. So the present study chooses Poland as the target country to analyze the challenges and opportunities Chinese enterprises will confront based on a combination of Hofstede's culture dimensions and PEST model and tentatively explores the concrete cross-culture management strategies in Poland. 


\section{Theoretical Framework}

\subsection{PEST Analysis}

PEST analysis is an analysis model examining the external environment and the global factors that may affect a business. It can provide a quick understanding of the external pressure facing a business and their possible constraints on its strategy. It is usually divided into four external influences on a business - political, economic, social and technological (Zhu, 2010).

Political analysis is to find how political development, locally, nationally, internationally affect the strategy of a business. There are some important political variants, including the nature of the ruling party, political system, economic system, government regulations, the changes of tax law, environmental protection law, industrial policy, investment policy, government subsidies, anti-dumping laws, etc. (Jiang, 2009).

Economic analysis is to find how economic factors may affect the business. Those economic factors include the spending pattern of consumers, economic conditions such as inflation and unemployment, fiscal and monetary policies of the government, as well as the changes in production and labor market etc. Economic environment consists of macroeconomic environment and microeconomic environment. The former refers to a country's population and its growth trend, the national income, the GDP as well as the level and speed of the national economic reflected in the above mentioned index. The latter refers to the consumer's income levels, preference, deposits and employment situation of the local area. All the factors mentioned above will directly determine the size of the market (Jiang, 2009).

Social analysis is to find what competitive advantage a business may gain by social changes. Social environment refers to the educational status, religions, customs, aesthetic views, and the values etc. of a community (Jiang, 2009). The educational level will determine people's hierarchy of needs; religions and customs will prohibit or resist certain activities; aesthetic views will influence people's attitude towards organizational goals, the mode of activity and the achievements. Some important social factors include demographic structure, life expectancy, average income, lifestyle, average disposable income, purchasing habits, moral concerns, gender role, investment propensity, average educational level, population control, energy conservation, etc.

Technology is vital for competitive advantage, and is a major driver of globalization. Technological analysis is to find how new technologies might affect the business activities. In addition to keeping abreast with the development of the technologies to which the enterprises directly related, much more information is to be known about the focus of the nation's technological development and investment, R\&D (research and development) expenditure, the speed of technology transfer and technology commercialization as well as patent protection, etc (Jiang, 2009).

\subsection{Hofstede's Cultural Dimensions Theory}

Culture shock is the root cause of culture difference (Feng, Ma \& Song, 2015). Generally speaking, the culture difference origins from various historical traditions and processes of social development and also results from the distinctive organizational culture; meanwhile, the individual competence of coping with culture conflicts varies greatly from person to person. Therefore, enterprises will confront culture shocks in one way or another. With culture difference exerting such a profound impact on economic activities, more and more experts embark on the research of cultural characteristics so as to help people understand and predict the behaviors and motivations of different culture communities. In the field of cross culture research, Geert Hofstede, the anthropologist from Holland, has been universally acknowledged as the most influential scholar. The cultural dimensions theory he put forward has been widely applied in cross culture practice and research. (Feng, Ma \& Song, 2015)

According to Hofstede, there exists an internal structure of different cultures (Feng, 2008). Based on a large scale survey on the employees of IBM regarding their national value differences, Hofstede ge neralized the structure into four basic dimensions, that is, uncertainty avoidance, individualism, power distance, and masculinity. Later, another two dimensions, the long-term orientation and indulgence, were added by Hofstede and other scholars.

The current study tries to combine PEST analysis model and Hofstede's culture dimensions into a theoretical framework (as seen in the following diagram) for the proposal of the cross-cultural management strategies to be applied in Poland. 


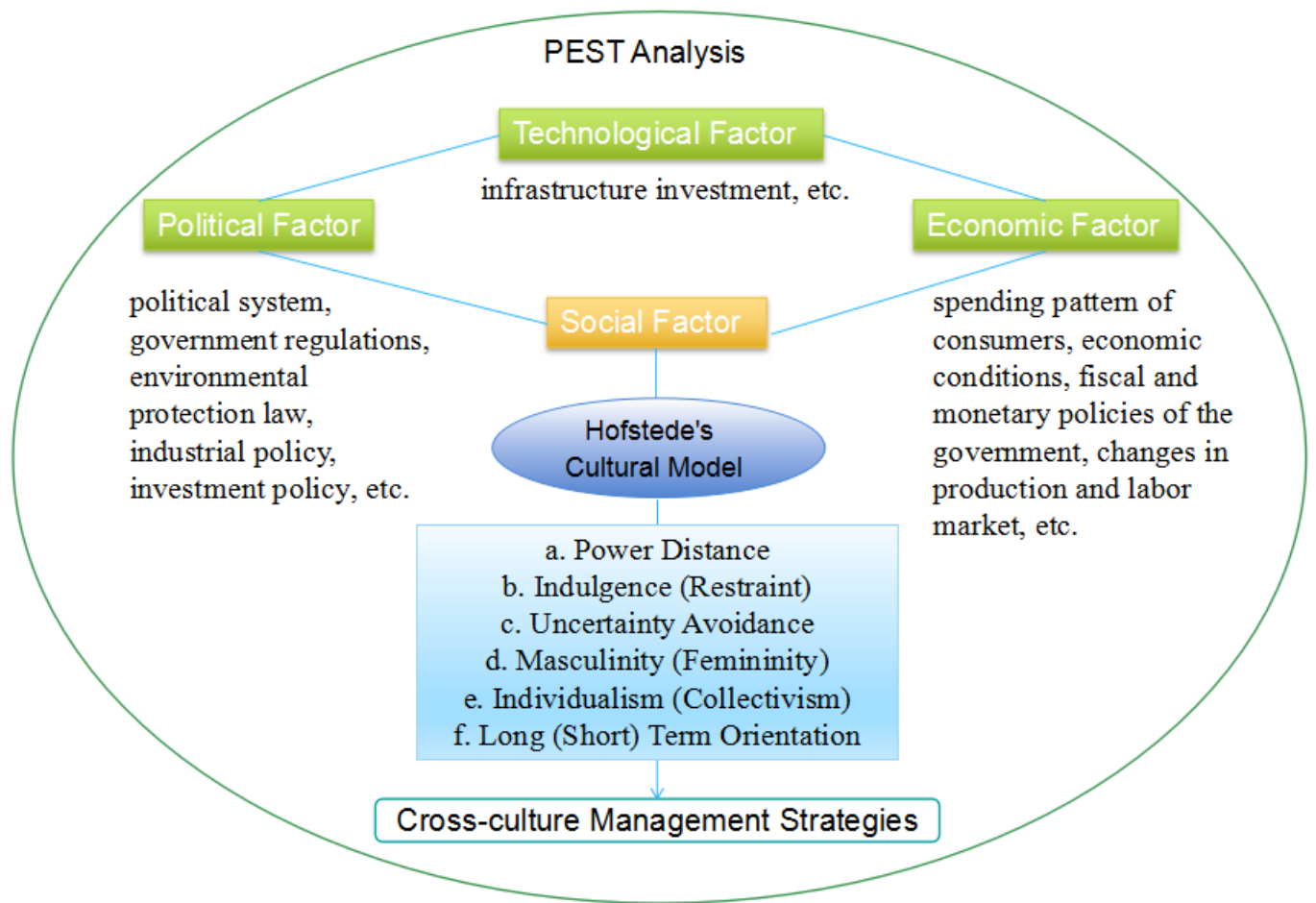

Figure 1. Theoretical Framework of the Paper

Based on the above framework, this paper will analyze the political, economic, and technological opportunities and the culture challenges (social factor) Chinese enterprises tend to confront in Poland and then put forward some tentative cross-culture management strategies for the reference of Chinese enterprises in Poland as well as in other countries.

\section{PEST Analysis of Poland}

Chinese enterprises will face lots of opportunities and challenges when investing in Poland. The present author will analyze in detail from the following four perspectives based on PEST model.

\subsection{Political Factor}

The friendly relationship between our two countries has a long history and Chinese enterprises will witness a favorable political environment when investing in Poland. In 1950s, Poland and China cooperated with each other closely. The bilateral relationship between two countries had de veloped in an all round way and the leaders had exchanged visits on a frequent basis (Du \& Huang, 2015). In international affairs, China supported Poland's initiative of nuclear-free zone in central Europe, at the same time, Poland backed China in the Korean War and its struggling of the reunification of the country as well as the restoration of its legitimate seat in UN. Though the relationship between two countries was deteriorated in the late 50s, it restored to its formal state in the 1990s and the two countries have exchanged more frequently after entering the $20^{\text {th }}$ century. In 2011 , president Komorowski visited China and the two countries made a communiqué about establishing strategic relationship, which indicates the further development of the partnership of two countries (Du \& Huang, 2015).

At present, the political system of Poland is stable, and is not vulnerable to some emergencies and political turbulence, indicating that Chinese enterprises can enjoy a safe and sound investment environment.

In recent years, some policies and mechanisms introduced by the government have vitalized the cooperation between two countries. In 2012, "16+1 Cooperation" mechanism was established in Warsaw. It is a new platform for China and 16 Central and Eastern European (CEE) countries to enhance their relationship and promote economic development. This new platform has not only expanded mutually beneficial cooperation, but has also deepened the China-EU comprehensive strategic relationship (He, 2016; Chen \& Wang, 2015). The most important is the Belt and Road Initiative put forward in 2013. It has facilitated the cooperation between two countries. The Long-term Development Strategy of Poland in 2030 as well as its emphasis on economic diplomacy corresponds with Chinese Silk Road Initiative. Polish government has enacted many incentive policies to attract foreign investments, including income tax exemption of the special economic zone, exemption of the real estate tax, as well as preferential tax deduction of R\&D center and of purchasing new technology. 
Polish government has introduced other mechanisms to attract foreign direct investments, for example, it provides cash subsidies for the investors on the part of the nation and European Union. Besides, it supports new investments and creates new jobs, the subsidies of which can reach as much as fifty percent of the aggregate investments. Polish government, together with EU, has helped the foreign investors through continuous market liberalization, property privatization, infrastructure improvement and investment promotion projects (Du \& Huang, 2015).

\subsection{Economic Factor}

Poland has gone through ups and downs in its economic development, but after 20 years' economical and social structure reform, the overall economy has been improved and now it performs well, which is manifested in its high GDP growth rate, the improvement of flexibility of labor market, the decrease of unemployment rate, and the stabilized investment environment.

The favorable economic conditions in Poland can be illustrated exactly as follows:

(1) The friendly relationship between China and Poland has greatly facilitated economic cooperation. In 2011, Poland and China has established Strategic Partnership and now it becomes the biggest trade partner of China in Central and Eastern Europe; China, at the same time, is Poland's biggest trade partner in Asia, all of which has demonstrated the sound development momentum between two countries and that Chinese enterprises are facing great opportunities of doing business with Poland.

(2) The economy of Poland performs well. After the global financial crisis in 2008, the economy of Poland slowed down for a while, but the vigorous domestic need and low degree of openness ensured its economy to develop in a sustainable way, and thus ranking among the few European countries whose economy kept rising during the crisis. For this reason, Poland has won the reputation of "the China in Europe" (Du \& Huang, 2015).

(3) The investment environment in Poland is stable. It can be further analyzed from the following three perspectives. (1) The anti-risk capability of the banking system is strong. It has been proved that Polish bank has strong resilience and needs no support from the country. Warsaw Stock Market is growing to be the leader of the area and the center of investment. During the past decade, the number of the listed companies has doubled and the daily turnover tripled. Actually, it is the biggest stock market in central and eastern Europe. (2) The labor market of Poland is flexible and resilient. It results from the vast domestic market and proficient and relatively cheap labor force. Therefore, Poland has become one of the most attractive destinations of investment. According to the report of World Investment Anticipation Survey, Poland takes the lead in the Central and Eastern Europe. The quality of labor in Poland is relatively high (according to statistics of EIS, it is above the average level) and the labor cost is much lower than the west Europe countries and lower than its neighbor countries such as Czech Republic. (3)Polish enterprises pay much lower income tax, which is $19 \%$ and is the lowest in the whole EU (Du \& Huang, 2015).

What's more, the implementation of the Belt and Road Initiative and the foundation of the Asian Infrastructure Investment Bank (AIIB) have contributed to the entry into Polish market. The advantageous geographical position of Poland is conductive for Chinese enterprises to invest and build up factories, or further explore the European market.

\subsection{Technological Factor}

The technological factor is mainly manifested in the infrastructure construction. Without advanced modern technologies, the convenient transportation among countries would be impossible.

The Belt and Road Initiative will give impetus to the construction of Poland as the transportation center of Central Europe and Western Europe. In April, 2013, the railway linked Chengdu with the city of Lodz in Poland was opened to traffic, which travels through Kazakhstan, Russia, and Belarus to end in Lodz, has greatly facilitated the trade and commerce between China and Europe (Du \& Huang, 2015). This railway has actually become the starting point for Lodz to cooperate with other cities in China, and Chinese enterprises can also take advantage of the convenient transportation to seek more invest opportunities in Poland. With the opening of Chengdu-Lodz railway and Chongqing-Sinkiang-Duisburg railway, the time and distance of transporting have been greatly shortened and the cost deducted, which attracts lots of Poland's importers and provides access for Chinese enterprises to invest not only in Poland, but also in the neighboring countries (Ji, 2015). Except those established railways, there are many other ways of transportation remaining to be perfected. In the light of its national development strategy, Poland pays more attention to the infrastructure construction of highway, railway, airport, shipping and Internet, which is conductive to the investment in Poland. According to the mayor of Lodz, their city is planning to cooperate with China to construct a project of Through Freight Traffic, devoting to 
establish a three-dimensional logistic network.

What's more, in the Budget of EU from 2014 to 2020, Poland is the biggest beneficiary. 82 billion euro of the Budget will be applied to scientific research, highway and railway construction as well as the public transportation amelioration (Wang, 2015).

In brief, the infrastructure construction in Poland backed by the government and EU will greatly facilitate Chinese enterprises' investment in Poland.

\subsection{Social Factor}

Poland, as a European Country, is subject to the influence of different customs, conventions, religions and social values when compared with China. So when Chinese enterprises invest in Poland, they are sure to confront culture conflicts, and the root cause of which is the value orientation. It is in this perspective that Chinese enterprises face the biggest challenge.

The value orientation of a culture can be explored through the lens of 6-dimension model constructed by Geert Hofstede. Hofstede's cultural scores provided a foundation for cross-cultural corporate training and international management courses in business and executive curricula; the indices not only aided generations of managers and practitioners working in international settings, but also have a profound impact in subsequent cross-culture research (Mladenović, 2017). The following bar chart is the comparison of the scores of Chinese value orientation and that of Poland. In the dimension of Power Distance, Masculinity and Indulgence, China and Poland are nearly the same, so the present study is conducted mainly from the following three perspectives.

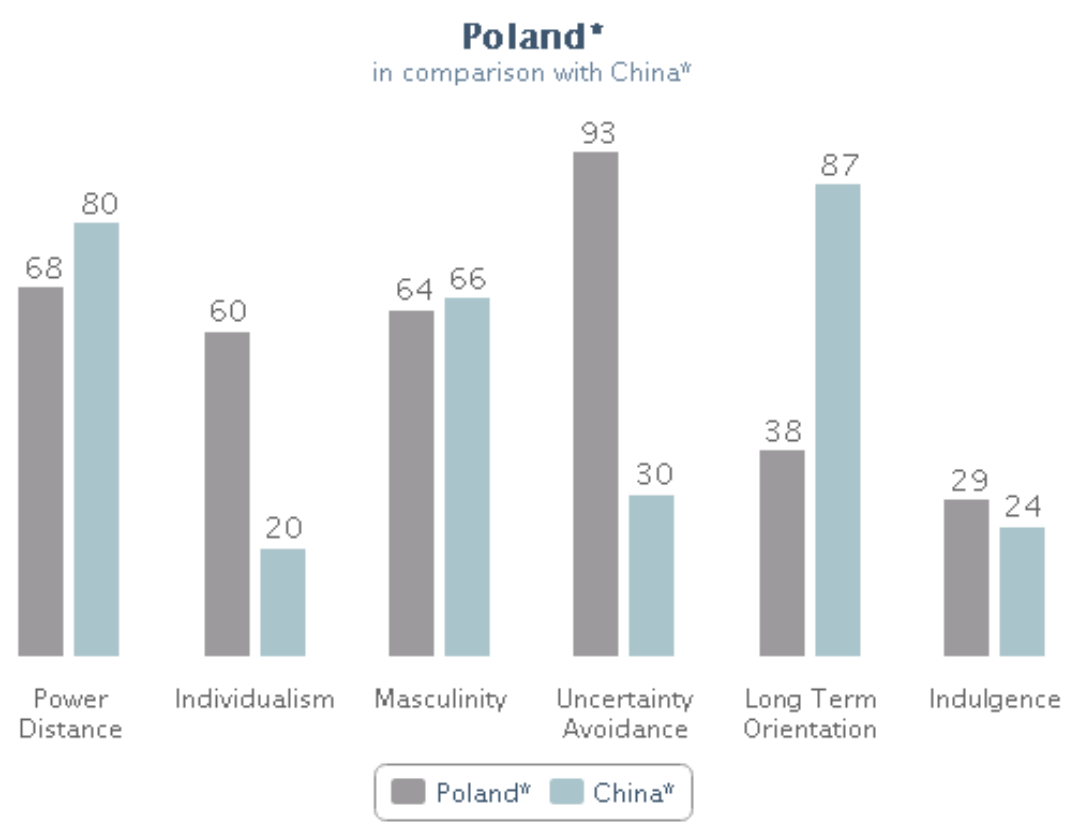

Figure 2. The Comparison of Value Orientation of China and Poland

\subsubsection{Individuality}

The fundamental issue addressed by this dimension is the degree of independence a society maintains among its culture. From the chart, we can see that China is a collective society while Poland is an indi vidualist society. This difference indicates that in cross-culture management, Chinese managers should respect the individuals, especially their privacy and freedom. The Polish culture houses a "contradiction": although highly individualist, the Polish need a hierarchy. This combination (high score on Power Distance and high score on Individualist) creates a specific "tension" in this culture, which makes the relationship so delicate but intense and fruitful once you manage it (Hofstede n.d.). Therefore, managers are advised to establish a second "level" of communication, having a personal contact with everybody in the structure, allowing to give the impression that "everybody is important" in the organization, although unequal (Hofstede n.d.).

\subsubsection{Uncertainty Avoidance}

In terms of Uncertainty Avoidance, China and Poland are quite different. Uncertainty Avoidance is defined as the extent to which the members of a culture feel threatened by ambiguous or unknown situations and have created 
beliefs and institutions that try to avoid these. In China, adherence to laws and rules may be flexible to suit the actual situation and pragmatism is a fact of life. The Chinese are comfortable with ambiguity and even the Chinese language is full of ambiguous meanings that can be difficult for Western people to follow (Hofstede n.d.). Polish people score 93 on this dimension, which indicates that they have a very high preference for avoiding uncertainty and maintaining rigid codes of belief and behavior. Polish people also have an emotional need for rules (even if the rules never seem to work) and time is so precious that they have an inner urge to be busy and work hard, so precision and punctuality are the norm, but innovation may be resisted and security is an important element in individual motivation.

As a result, when entering into Polish market or employing Polish workers, Chinese enterprises should pay special attention to the rules and disciplines of the company and respect individual's freedom. In the team management, internal rules and standards can be stipulated to avoid the uncertainty and ambiguity. What's more, the enterprises can invite a certain number of experts to establish the authority of the company (Gao, 2015).

\subsubsection{Long Term Orientation}

This dimension describes how every society has to maintain some links with its own past while dealing with the challenges of the present and future. Poland, scores low on this dimension, is a normative society, which prefers to maintain time-honored traditions and norms while viewing societal change with suspicion. They have a relatively small propensity to save for the future and a focus on achieving quick results. However, China, on the other hand, takes a more pragmatic approach. People believe that truth depends very much on situation, context and time. They show an ability to adapt traditions easily to changed conditions, a strong propensity to save and to invest and also the thriftiness and perseverance in achieving results (Hofstede n.d.).

In cross-culture management, Chinese enterprises can assign some short term programs to the Polish workers since if the project lasts too long a period, they may lose their patience and quit in the middle of the project. When making a decision, managers should synthesize the opinions from both Chinese party and the Polish party as two groups of people from different cultures may take a totally different perspective when viewing the same problem, the company can have different opinions confronted and finally come up with a more appropriate plan.

From the above PEST study on the investment environment in Poland, it is obvious that there are many favorable conditions there. Given the grand scheme of things, enterprises cannot change the political, economic and technological factors, but they can enhance their intercultural communication competence. Chinese enterprises can enjoy the supporting policies enacted by the governments and benefit from the opportunities brought by the advanced technologies; however, in order to be successful in the investment, Chinese enterprises should attach greater importance to the different cultures of our two countries and formulate concrete cross-culture management strategies. Therefore, in the following part this writing will propose some tentative strategies based on the previous study of cross-culture management.

\section{Cross-culture Management Strategies}

In cross-culture management, conflicts can frequently rear their heads since people's behaviors are greatly influenced by the culture and values deeply rooted in their mind. Therefore, when entering into the Polish market, Chinese enterprises should effectively tackle the problems caused by culture shock and culture conflicts. There are some tentative strategies for the reference of Chinese enterprises.

\subsection{Investigating the Local Markets and Identifying the Culture Differences}

It is widely acknowledged that culture conflicts are caused by culture diversity. So in cross-culture management, it is imperative to identify the culture differences in the target country. Poland, a European country, as has analyzed above, has different customs and values when compared with an Asian country as China. So, when Chinese enterprises enter into Polish market, managers should do some research on the local culture. Only by identifying the existing culture differences can we be poised to seek the common grounds and make specified strategies. To identify the culture differences has two shades of meanings: first is to understand how the culture of the host country (Poland) will affect the local employees' behavior; second is to understand how the culture of the home country (China) will influence its designated managers to the host country. So, it is not enough to know its own culture. Only by equipping oneself with full knowledge of both the host country and the target country can it be possible to response to the cultural diversity proficiently and effectively.

Culture diversity falls into three types: different basic values, different living habits and different professional knowledge. The basic values of the local people are hard to change; differences on living habits can be alleviated through cultural exchanges, though it takes time; differences incurred by management styles and management skills can be overcome by learning from each other, which is quite easy (Guan, 2012). 
Whatsoever, only by identifying the existing culture differences can it be possible for us to take pertinent managerial measures.

\subsection{Cultivating Intercultural Communication Competence of the Cross-culture Employees}

Cultivation here means that the company should cultivate the intercultural communication competence of the employees. The most direct and efficient way of cultivating such kind of competence is to conduct intercultural training. On one hand, the company can expose their employees to the values, ethics, customs as well as the regulations of the foreign cultures so as to enhance their understanding of the other culture and improve the culture sensitivity. As a result, employees will understand the differences and respect the differences, minimizing the culture conflicts and enhancing the problem-solving ability so as to create a harmonious interrelationship; on the other hand, the training programs can develop employees' observation ability as well as face-to-face communicative competence, making it possible for them to learn and understand exotic culture in the daily business environment (Gao, 2015). What's more, the intercultural training can convey the corporate culture to the employees, thus making the company more cohesive and employees more loyal and kindling the enthusiasm as well as the belongingness of them.

The major contents of intercultural training include cultural sensitivity, foreign cultural knowledge, language competence, cross culture communicating skills and cross culture conflict management (Guan, 2012). Language Training is of great importance to the direct communication of the employees. Through the training of language skills and related cultures, the barriers will be removed and communication will be smoother. Nowadays, the culture sensitivity training is gaining more and more importance, the goal of which is to improve people's resilience and adaptability to different cultures. The concrete measures taken are to assemble employees with different culture background to have a specific culture training, field study, situational dialogue as well as role plays, etc. so as to break the cultural barriers and shake off the bondage of roles.

\subsection{Acculturating to the Local Society and Making Innovation Based on Culture Fusion}

When communicating with another culture, a feasible principle is to 'think globally and act locally". In terms of design philosophy, organizational structure, strategies making and motivation system, the company should fully consider the culture background of the local people and enact diversified policies to penetrate the market and improve their degrees of satisfaction. When facing the culture conflicts, managers should respect the host culture rather than criticizing it without discrimination or even impose the home culture upon them.

The diversified culture, if well used, can generate enormous benefits to the whole company. During the process of management, managers could employ the positive factors of different cultures and encourage different ide as and opinions of employees so as to make the decision making process more democratic and the decision itself more scientific. To some extent, acculturation entails the meaning of glocalization, which is a compound word of globalization and localization. According to Kraidy, glocalization refers to a new cultural hybrid and change of norms and practices aimed at adjusting to local mindsets. It is important because it is prevailing in contemporary society and only when adaptation to foreignness is successful can glocalization become successful (Dou, 2012). Acculturation does not mean discarding the home culture, it means that a sort of balance or compromise should be explored between two cultures, seeking common grounds while reserving differences.

Based on acculturation, the enterprises can take advantage of this bi-cultural background to cultivate its distinctive corporate culture and establish a communication mechanism, thus creating an enabling environment inside the company. In order to be well received in the host market, managers should be acculturated and glocalized to the host culture and give full play to its advantage of bi-cultural background.

\section{Conclusion}

After analyzing the potential opportunities and challenges Chinese enterprises tend to confront in Poland based on PEST model and Hofstede's culture dimensions, this writing gets the following findings:

(1) The Belt and Road Initiative has provided a great opportunity for Chinese enterprises to seek investments in Poland and there are many favorable and available conditions in both countries. Politically, the friendly relationship between our two countries and the relevant policies introduced by the governments will greatly facilitate the investments. Economically, the stable domestic market and sound economic performance in Poland provides an enabling environment for investments. Technologically, the infrastructure construction backed up by advanced technologies makes the exchanges more convenient.

(2) Though there are many opportunities, the challenges cannot be overlooked. Poland, as a European Country, is different from China in customs, conventions, religions and social values which should be taken into account. For instance, Poland is an individualist society with high Uncertainty Avoidance and Short Term 
Orientation, according to which internal rules and standards can be stipulated to avoid the uncertainty and ambiguity. So in the cross culture investments, Chinese enterprises should pay much attention to those cultural differences and come up with feasible coping strategies.

Based on the above findings, this writing supplies the following tentative cross-culture management strategies which are referential for Chinese enterprises in other countries:

(1) Investigating the local markets and identifying the culture differences;

(2) Cultivating intercultural communication competence of the cross-culture employees;

(3) Acculturating to the local society and making innovation based on culture fusion.

To put it briefly, when seeking investments in Poland, Chinese enterprises should take full advantage of the favorable political, economical, and technological conditions on one hand and face the cultural challenges in a prudent and targeted way on the other. Only by managing different cultures efficiently can Chinese enterprises get out of the culture dilemma and maximize their profits.

\section{References}

Chen, B., \& Wang, F. (2015, May 29). Poland Expecting to be the Biggest Strategic Partner under OBOR. Chongqing Daily. Retrieved from: http://cqrbepaper.cqnews.net/cqrb/html/2015-05/29/content_1840121.htm

Dou, W. L. (2012). Introduction to Intercultural Communication. Beijing: University of International Business and Economics Press.

Du, Y. Y., \& Huang, J. H. (2015, May 29). An analysis of Political Risks of OBOR Investment in Poland. China. org. Retrieved from: http://opinion.china.com.cn/opinion_12_130912.html

Feng, M., Ma, H. B., \& Song, C. P. (2015) Cultural Dimensions Theory and Cultural Intelligence Theory—Double Swords for Cross-cultural Management. Journal of SUIBE, 22, 49-57.

Feng, N. X. (2008). Introduction to Hofstede and the Culture Dimensions. International Business, 1, 37-41. https://doi.org/10.1016/j.ibusrev.2008.02.007

Gao, C., \& Ma, C. Z . (2015). The Cross-culture Management of Chinese Enterprises Going out in One Belt and One Road Strategy. Human Resources Development of China, 19, 14-18.

Gu, Y. (2011). A Study on Cross-cultural Management of Multinational Enterprises-based on Coco Cola Company of China . MA. Xi'an International Studies University, Xi'an, China.

Guan, X. L., \& Luo, L. J. (2012). The Management and Administration of Multinational Corporations. Beijing: Renmin University of China Press.

He, S. (2016, April 25 ). Poland's FM: OBOR Provides the Most Promising Platform for EU-China Cooperation. China. org. Retrieved from: http://news.china.com.cn/2016-04/25/content_38320358.htm

Hofestede Cultural Dimension. (2015, May 21). Retrieved from: http://geert-hofstede.com/poland.html

Ji, P. J. (2015, June 24). Poland Take a Ride on OBOR. China Daily. Retrieved from: http://paper.people.com.cn/rmrb/html/2015-06/24/nw.D110000renmrb_20150624_3-03.htm

Jiang, B. (2009). Research on Development Strategy of Sunvim Group. MA. Qingdao University of Science and Technology, Qingdao, China.

Li, Y. L. (2006). Intercultural Shock and Inter-Cultural Management. Scientific Socialism, 2, 70-73.

Mladenović, S. S., Mladenović, I., Milovančević, M., \& Aleksandra, T. K. (2017). Cross-cultural dimensions influence on business internationalization by soft computing technique. Computers in Human Behavior, 75 , 865-869. https://doi.org/10.1016/j.chb.2017.06.035

Sun, C. R., \& Liu, Y. Y. (2017) One Belt One Road Initiatives and the Export Growth of China to the Related Countries. Journal of International Trade, 2, 83-96.

Tang, Y. Z., \& Lu, W. (2005). Cross-cultural Management Research and Enlightenment in Foreign Countries. Management Frontier, 5, 25-28.

Wang, L. N. (2015, July 6). Connecting with Poland Through OBOR, Financial Magazine. Retrieved from: http://magazine.caijing.com.cn/20150706/3919570.shtml

Wei, Q. (2015, June 19). Poland Responding to China's the Belt and Road Initiative. China News. Retrieved 
from : http://www.chinanews.com/gj/2015/06-19/7356296.shtml

Yang, B., Chen, W., Lin, C., \& Song, L. (2016). Culture Strategies of Chinese Enterprises in Cross-culture Management Under the Belt and Road Initiative. Management World, 9, 174-175.

Zhao, X. M. (2014). Cross-Cultural Management Research Thai Enterprises to Enter the Chinese Market. Economic Vision, 21, 96-98.

Zhu, W. Z. (2010). Introduction to International Business Management. Beijing: University of International Business and Economics Press.

\section{Copyrights}

Copyright for this article is retained by the author(s), with first publication rights granted to the journal.

This is an open-access article distributed under the terms and conditions of the Creative Commons Attribution license (http://creativecommons.org/licenses/by/4.0/). 